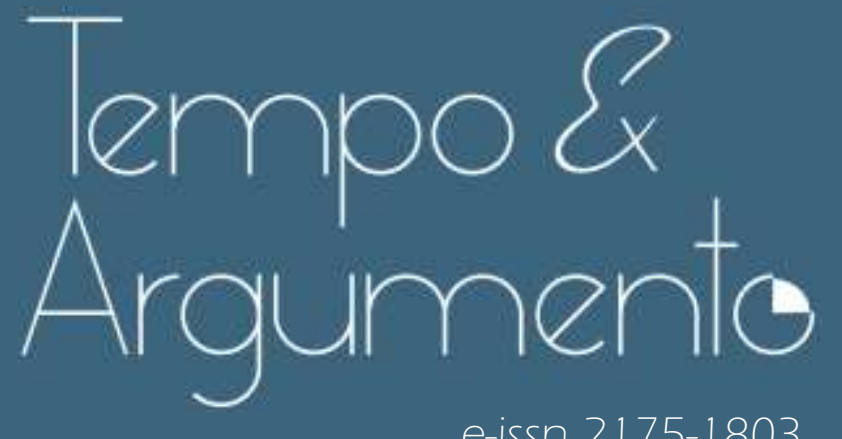

e-issn 2175-1803

Medo, intolerância, resignação: algumas leituras
sobre a imigração contemporânea na Itália

Luís Fernando Beneduzi

Doutor em História pela Universidade Federal do Rio Grande do Sul (UFRGS).

Professor Titular da Università Ca Foscari Di Venezia (UNIVE).

Veneza - ITÁLIA

unive.it/data/persone/5590982

luis.beneduzi@unive.it

(D) orcid.org/0000-0003-2885-5548

Para citar este artigo:

BENEDUZI, Luís Fernando. Medo, intolerância, resignação: algumas leituras sobre a imigração contemporânea na Itália. Tempo e Argumento, Florianópolis, e0 103, 2021. Número especial.

do) http://dx.doi.org/10.5965/21751803ne2021e0103 


\title{
Medo, intolerância, resignação: algumas leituras sobre a imigração contemporânea na Itália
}

\begin{abstract}
Resumo
Diversos estudos têm mostrado como o medo e a ansiedade são emoções que têm marcado a sociedade contemporânea, com novos e velhos detonadores desses sentimentos os sujeitos no mundo atual. O outro, a alteridade, tem sido no tempo objeto de preocupação, de medo, nas diferentes coletividades humanas. No que tange aos processos migratórios, observa-se como esse temor em relação ao diverso tem construído estereótipos, muros, intolerância, sentimentos que muitas vezes se escondem na ideia de "integração", ou seja, na busca de anular aquilo que é característico do outro, ao interno da sociedade de acolhida. Por outro lado, no sujeito migrante, a busca de "integração" pode mostrar - diferentemente - a resignação que marca o esforço para obter aceitação e reconhecimento. O objetivo deste artigo é analisar - a partir da metodologia da história oral - o fenômeno da imigração contemporânea na Itália, com ênfase nos sujeitos provenientes da América Latina, procurando entender os recursos utilizados por esses indivíduos para serem "aprovados" no contexto da terra de chegada. Nesse sentido, a ruptura de uma corrente de desconfiança, construída como consequência de um medo compartilhado socialmente, permitiria um processo de inclusão, ou seja, de inserção do outro na comunidade de acolhida, sem a necessidade de despojar-se de si.
\end{abstract}

Palavras-chave: migração latino-americana; Itália contemporânea; sensibilidade; memória; inclusão social.

\section{Fear, intolerance, resignation: some readings on contemporary immigration in Italy}

\begin{abstract}
Several studies have shown how fear and anxiety are emotions that have marked contemporary society, with new and old triggers of these feelings affecting subjects in today's world. The other, otherness, has been an object of concern, fear, in various human collectivities over time. With regard to migratory processes, we notice how this fear of what is different has constructed stereotypes, walls, intolerance, feelings that are often hidden in the idea of 'integration,' i.e. in the search to annul what characterizes the other, within the host society. On the other hand, in the migrant person, the search for 'integration' can show - differently - a resignation that marks an effort to gain acceptance and recognition. This article aims to analyze - relying on the oral history methodology - the phenomenon of contemporary immigration in Italy, with an emphasis on people from Latin America, seeking to grasp the resources used by these individuals to be 'approved' in the context of the land of arrival. Thus, the break of a chain of distrust, built as a consequence of a socially shared fear, would enable an inclusion process, i.e. the insertion of the other in the host community, with no need to divest from oneself.
\end{abstract}

Keywords: Latin American migration; contemporary Italy; sensibility; memory; social inclusion. 
Como afirma Peter Stearns, inúmeros estudos recentes reivindicam o medo como a emoção predominante no quotidiano da sociedade contemporânea (STEARNS, 2006); um sentimento - entendido enquanto resultado de uma experiência emocional - que talvez esteja menos marcado pelo paradigma religioso, como destacava Jean Delumeau, na década de 70 do século passado (DELUMEAU, 1978), mas que - mesmo em uma sociedade secularizada - apresenta uma força motriz de grande importância. Ainda que a divindade tenha perdido força enquanto detonador do medo e da ansiedade, um mundo invisível individuado pela ciência, a partir do século XIX - especialmente observável no contexto hodierno da pandemia de covid-19 -, tomou o seu lugar. Por outro lado, a alteridade - satanizada não mais por critérios místicos e religiosos, mas em nome da defesa de uma identidade nacional e de uma nação atacada - manteve-se como elemento desencadeador do medo.

Na verdade, como indica Joanna Bourke, "medo é sobre relações de poder e resistência. A emoção aparece como uma conexão entre o sentir ou a experiência psicológica e o 'estar no mundo' ou o agir como seres sociais" (BOURKE, 2003, p. 129). Ou seja, o medo - cujo objeto de perigo se apresenta diante do indivíduo - ou a ansiedade - construída a partir de uma ideia menos concreta do perigo - são criados em um processo de relação entre as emoções e a experiência social dos sujeitos. Não existem a priori, mas se forjam nas interações concretas, simbólicas, imaginadas que os seres humanos produzem ao interno de suas comunidades, pois, mesmo sendo parte do viver pessoal, é também elaborado de maneira coletiva. Considerando que, como diz Stearns (2006, p. 478), "na psicologia behaviorista, por exemplo, com suas afirmações de que a humanidade possui muito poucos medos inatos e que, com uma organização cuidadosa, a criação dos filhos pode produzir indivíduos livres do medo", o que se observa no mundo contemporâneo é uma grande máquina de produção do medo, que envolve as diferentes coletividades humanas; emoção muitas vezes imaginária, mas que adquire uma força real e concreta na determinação das ações pessoais e coletivas. 
De fato, existe um uso político importante do medo, muitas vezes utilizado para distrair ou para cooptar; no entanto, ao mesmo tempo, a própria política muitas vezes é movida pelo mesmo sentimento:

Medo, desde cima, tem sido cada vez mais utilizado para motivar decisões políticas, e o processo é novo - ao menos nestas proporções - e decididamente alarmante. Robin [Corey Robin] certamente sacode os conservadores, que desviam a atenção dos problemas sociais reais, invocando o medo, mas, com Shklar [Judith Shklar] ele não identifica a abordagem somente com os conservadores, mas com uma mudança mais ampla no processo político. (STEARNS, 2006, p. 479)

Portanto, problemas sociais complexos, que envolvem dinâmicas de exploração do trabalho, por exemplo, nas sociedades contemporâneas, podem ser explicados de uma maneira simples com a construção de um medo: a perda de trabalho causada pela chegada de imigrantes. Nesse caso, a política não precisa encontrar soluções estruturais ao problema, mas é suficiente propor o bloqueio dos fluxos migratórios, em uma apresentação populista da nação e da antinação, "resolvendo" desta maneira - na construção discursiva - o problema. Como os fluxos nunca serão bloqueados completamente, esse tipo de narrativa continuará a garantir os votos de eleitores que se sentem ameaçados por esse inimigo externo e representados por grupos políticos que prometem uma fácil salvação.

Ao mesmo tempo, aquilo que era uma ansiedade - a perda do emprego uma aflição, angústia, que permanecia no nível da abstração e, dessa forma, não consentia a busca de uma solução, agora se transforma em um medo, ou seja, em algo concreto que pode ser neutralizado:

Em estados de medo, os indivíduos estão conscientemente aptos (ou acreditam estarem aptos) para adotar medidas para neutralizar ou fugir do objeto perigoso, quando esta ação voluntária falha, vivem a experiência subjetiva da 'ansiedade'. No entanto, a capacidade de 'neutralizar ou fugir' é uma questão de relações de poder dentro de comunidade históricas - não uma diferença fundamental entre o objeto ou estado que causam uma resposta emocional. (BOURKE, 2003, p. 127, grifo do autor)

Dessa maneira, aquilo que representava uma incerteza - a ansiedade pode ser mudado para algo conscientemente identificável, um medo, a partir do 
processo de reconhecimento de um inimigo, daquele que é o responsável concreto e direto pelo amedrontamento. Obviamente, este inimigo termina por encarnar os elementos negativos que ocasionam a ansiedade-medo, acaba por ser criminalizado para justificar uma ação forte de correção, controle e subordinação desse grupo subalterno, no caso, o imigrante:

A insegurança da ansiedade pode ser arrebatada pelo processo de designer um inimigo (plausível ou não), convertendo a ansiedade em medo [...]. Em outras palavras, os debates sobre o medo do crime são um reflexo da ansiedade de uma transformação mais geral e são usados para legitimar o controle sobre os grupos subordinados. (BOURKE, 2003, p. 127)

No contexto imigratório, como se busca mostrar no presente artigo, a ideia de integração se transforma em uma forma de controle do inimigo, de submissão e assujeitamento, na busca de superar o medo da alteridade, pois trabalha na eliminação das características diferenciadoras em relação à sociedade de chegada. Na medida em que se despoja de si mesmo, o imigrante pode ser aceito, mesmo que em uma forma sempre subalterna, mas menos ameaçadora, na coletividade que o acolhe: ameniza a imagem ameaçadora que o caracteriza, porque está vivendo um processo civilizatório.

Na trilha dessa discussão, procura-se analisar, no presente artigo, como o crescente medo do outro - construído na Itália contemporânea, a partir dos desembarques de massa de albaneses, na década de 1990, e chegando até aqueles em Lampedusa nos dias atuais - foi criando um espaço de intolerância e de incapacidade de aceitar a alteridade enquanto tal. Dessa maneira, colabora com a construção de um forte discurso transversal no mundo político e nos meios de comunicação acerca da necessária integração de um processo disciplinador dos imigrantes, que impedisse a deterioração da nação com vícios e problemas por eles trazidos, que a invasão fosse controlada e o "bárbaro" domesticado.

\section{A imigração na Itália, um fenômeno recente, e a construção do medo}


Mesmo sendo um país com uma longa tradição emigratória, a ideia da Península Itálica como um lugar de chegada de imigrantes é muito recente, pois somente a partir das últimas décadas do século XX começou-se a observar um fenômeno - mesmo que irregular - de imigração. Portanto, os habitantes da península estão habituados com as partidas, sejam elas temporárias, muito comuns no período anterior à emigração de massa iniciada nas últimas décadas do século XIX, seja enquanto experiência "permanente", como aquela que marcou os deslocamentos para o continente americano, entre os séculos XIX e XX.

Como fenômeno de impacto político, social e jornalístico, a experiência da imigração remonta aos anos 90 do século XX, quando os primeiros albaneses, durante o colapso do comunismo na Europa Oriental, começaram a desembarcar na Puglia (região da Itália meridional, colocada no mar Adriático, de frente para a Albânia) $)^{1}$. A imagem das chegadas diárias de imigrantes que se jogavam dos navios e nadavam até a praia ocupava as primeiras páginas dos jornais e os espaços centrais dos telejornais. Ainda que não em um primeiro momento, pouco a pouco foi sendo construída uma ideia de invasão, associada aos desembarques, e - ao mesmo tempo - uma narrativa com relação ao governo albanês, que abria as portas das prisões para mandar todos os bandidos para a Itália. Desde então, o discurso do medo começou a ser construído e, logo em seguida, o seu uso político, pois a invasão desses bárbaros contemporâneos devia ser bloqueada para que a nação fosse protegida.

Bonifazi (2007) indica que, quando os primeiros albaneses desembarcaram, em 1990, toda a cidade de Brindisi, junto a representantes da política local e nacional, correu para receber e acolher os refugiados que escapavam do comunismo. Mesmo as ondas seguintes de chegadas provenientes da Albânia, entre março e agosto de 1991, provocaram uma grande solidariedade da parte da população local, em resposta também à incapacidade demonstrada pela máquina pública de acolher os refugiados, fato que, naquele

\footnotetext{
Mesmo considerando que as primeiras ondas migratórias remontam às décadas de 60 e 70 do século XX, como consequência do grande crescimento econômico vivido naquele período, com a chegada principalmente de filipinos e tunisinos (EINAUDI, 2007), vai ser somente com os desembarques dos albaneses, numericamente e imageticamente mais impactantes, que o fenômeno começará a ganhar uma conotação mais negativa e destrutiva.
} 
momento, ainda suscitava forte crítica por parte dos meios de comunicação e da opinião pública. Pouco a pouco, o aumento do fenômeno foi transformando a percepção da sociedade italiana com relação a essas chegadas, passando semanticamente da indicação de refugiados políticos proveniente da Albânia, a imigrantes, com a consequente passagem da ideia de acolhida àquela de controle ${ }^{2}$. Os próprios telejornais funcionaram como os primeiros instrumentos na construção do medo que rompia com a rede de solidariedade: através da difusão de um vocabulário bélico, com uso de termos como "ameaça" ou "exército que invade/toma de assalto", a nação começava a ser representada, nos meios de comunicação, como uma fortaleza que devia ser protegida.

Observa-se, no contexto dos últimos 30 anos, um grande momento de transformação, pois o italiano não é mais, como nas décadas anteriores, aquelas da emigração de massa de finais do século XIX, o outro na casa de alguém; neste momento tudo muda, porque agora, nesta passagem de terra de partidas a terra de chegadas, é o italiano que recebe o outro na sua casa. Na verdade, o novo fenômeno significa também colocar em discussão percepções identitárias, dinâmicas de reconhecimento cultural, o medo em relação ao risco de perda de uma tradição que se imagina imutável. Mesmo na terra das rivalidades e diferenciações culturais entre cidades contíguas, que se constrói com a ideia da grande variedade, também dialetal, entre as diversas regiões que a compõem, o aumento exponencial das chegadas acaba produzindo o nascimento do mito de uma nação homogênea. Neste novo espaço encantado da comunidade imaginada (ANDERSON, 2018), representada nos meios de comunicação e construída nos discursos políticos, especialmente aqueles de extrema-destra, a alteridade que "invade", vem destruir uma suposta comunhão de valores, de tradições e de dinâmicas culturais compartilhadas.

\footnotetext{
2 Embora destacando um significado político usado pela comunidade italiana para refugiados e imigrantes, no contesto da imigração albanesa da década de 1990, neste texto, utiliza-se o conceito de migração indicado pela UNESCO, extraído de Linhard e Parsons (2019, p. 4), que identifica o fenômeno com "o cruzamento da fronteira de unidades políticas ou administrativas por um período mínimo de tempo. Isso inclui o movimento de refugiados, pessoas deslocadas, pessoas desenraizadas, assim como migrantes econômicos." Como relação aos ítalobrasileiros, dar-se-á ênfase à condição deles como migrantes, independentemente de terem sua cidadania italiana reconhecida ou não.
} 
Além disso, na imprensa escrita e falada ganha sempre mais espaço a associação entre imigração e criminalidade, ou clandestinidade, em um processo, demonstrado teoricamente por Bourke (2003), de legitimação de ações de controle dos grupos subalternos, que acaba por criar um imaginário coletivo que vincula imigrante e ilegalidade. Segundo Bonifazi (2007), a terminologia que é usada para indicar os imigrantes, e que colabora para a construção desse imaginário, é tomada de adjetivos, verbos e substantivos com um sentido negativo: ilegais, sem documentos ou indocumentados, irregulares, clandestinos. De diferentes maneiras, esses indivíduos que continuam a chegar, em fluxos mais ou menos constantes, nos últimos 30 anos, são identificados à produção de insegurança, algo que perturba a legalidade e a normalidade das relações quotidianas; alguma coisa que deve ser interrompida, impedida, travada.

Não se observa somente uma preferência - nos meios de comunicação pela associação dos imigrantes com matérias jornalísticas de natureza criminal ou com a justiça penal, com quase nenhum espaço para temáticas propositivas de políticas públicas ou de utilidade social, mas, além disso, nota-se um conjunto de notícias que enfatizam muito mais os delitos cometidos pelos imigrantes do que aqueles perpetrados por italianos (CALVANESE, 2011). Nas "páginas" da crônica policial, com relação aos diferentes tipos de crimes, quando o delito é cometido por um imigrante, a associação a uma identificação nacional, ou seja, ao país de proveniência, é imediata ou ao seu lugar de extracomunitário. Mesmo nos casos em que a pessoa em questão tenha obtido a cidadania italiana, às vezes como consequência do fato de ter nascido na Itália, é enfatizada a sua origem ou proveniência geográfica, como que demarcando uma diferença entre esses sujeitos e os "verdadeiros italianos". Por outro lado, não se encontra a mesma regra de identificação nacional quando o criminoso é um italiano, na maioria das vezes a nacionalidade é silenciada.

O crescimento do medo e da ansiedade com relação a este outro, o imigrante, é também uma consequência direta da forma como os meios de comunicação constroem e narram as notícias, as quais são recebidas pela população local, através da imprensa escrita e falada, que se transforma em instrumento de difusão e amplificação, contribuindo à fabricação de uma 
sensação disseminada de temor. Nos últimos anos, com o advento dos jornais online e dos espaços para os comentários dos leitores, esse tipo de fonte se transforma em material fundamental para compreender o impacto das notícias junto à sociedade civil:

Foram sempre os jornais que nos contaram. Provocando a nossa reação. Basta ler os comentários presentes no artigos das edições online dos jornais: no site do "Corriere della Sera» dezenas de leitores exprimiam incredulidade, indignação, mas sobretudo medo: medo de se tornarem "estrangeiros na própria pátria», «hóspedes na nossa casa» por causa de «uma imigração selvagem»; medo de ter que dar hospedagem para "todas as mulheres grávidas do terceiro mundo, vinda para parir às custas da comunidade»; medo de ver desaparecer a «nossa cultura» por causa da chegada de um número indeterminado de «muçulmanos» (que poderiam fazer «milhões de filhos e impornos a sharia» decretando nada menos que «o fim da civilização». (FALOPPA, 2011, p. 43, grifo do autor)

Como se pode observar, a ansiedade das transformações inerentes à sociedade contemporânea é transformada em medo a partir da individualização de um culpado, o imigrante. A perda das certezas e a insegurança do presente adquirem um inimigo concreto contra o qual se pode lutar de diferentes maneiras; portanto, existe a possibilidade de fazer alguma coisa para garantir a segurança do presente: impedir o fenômeno imigratório, controlar os desembarques, bloqueá-los na Líbia, ajudá-los na casa deles. Os discursos políticos animam e agitam o debate público com ideias, na maioria das vezes, tão mágicas quanto impossíveis, mas que permitem imaginar supostas e abstratas ações neutralizadoras que possam eliminar o perigo e acabar com a ansiedade. No entanto, enquanto a fortaleza continuar a ser expugnável, a integração, junto ao controle, se transforma na ação necessária para garantir proteção e conter o perigo.

\section{Integração como limitação do perigo interno}

Desde os anos 90 do século XX, como apontado anteriormente, quando tem início o problema imigratório, tem se verificado um contínuo aumento da percepção - por parte da opinião pública da Península - da imigração enquanto um perigo para a nação. Sobretudo, nota-se o uso político dessa negatividade 
atribuída à chegada de imigrantes, com promessas de repatriamentos e de defesa da italianidade. A este propósito, à imagem de invasão, associada ao fenômeno, é acrescentada aquela de não integração, dos imigrantes que não querem aceitar as normas da sociedade italiana e não querem se assujeitar às suas tradições, que não usam o idioma de Dante nos seus quotidianos, mas mantêm suas línguas de proveniência.

Portanto, além do repatriamento, apresenta-se uma outra solução possível, que permite ao menos a redução do risco, a ativação de processos de integração. Em todos os campos políticos, de modo transversal nos meios de comunicação, de maneira difusa na sociedade, "integrar" se transformou na palavra do momento e em um dos objetivos centrais das políticas públicas. No entanto, é fundamental colocar-se a questão sobre o que se entende pelo termo "integração" e o que pode significar na vida dos imigrantes esse tipo de experiência.

Permanecendo no âmbito da língua italiana, a enciclopédia Treccani, uma das mais importantes na Península Itálica, apresenta uma perspectiva de leitura muito interessante sobre o verbete "integração", associando-o à ideia de incompleto, de algo que deve ainda ser concluído/terminado/corrigido:

Integração: Em sentido genérico, o fato de integrar, de tornar inteiro, pleno, perfeito, aquilo que é incompleto ou insuficiente para um determinado fim, acrescentando o que for necessário ou suprindo o defeito com os meios adequados. (TRECCANI, 20--)

Dessa forma, desprovido daqueles que são os valores míticos desta comunidade imaginária, conceito analisado por Anderson (2018), a necessidade de integrar o imigrado assume o significado de suprir os seus defeitos com relação à italianidade. Esse indivíduo chega imperfeito e deve ser aperfeiçoado através da ação da sociedade civil, mas, sobretudo, por parte do Estado, para poder se tornar parte - mesmo que subalterna - da sociedade nacional. É importante enfatizar que - em nenhum momento - quando se fala de integração, se parte do pressuposto que esses sujeitos possam chegar com uma própria cultura de proveniência, que deve fazer parte do processo de interação social. Consequentemente, nesse processo não se observa uma preocupação 
com aquilo que o imigrante aporta à coletividade que o recebe, o enriquecimento cultural e social que é fruto do fenômeno migratório; preocupa e gera temor a capacidade subversiva desses indivíduos, a possibilidade de que estes venham a comprometer o tecido social.

É interessante esse duplo discurso na sociedade italiana, que talvez possa ser associado ao eurocentrismo que historicamente reforçou o binômio civilização-barbárie, no qual o primeiro termo era vinculado às nações europeias, que partiam para levar progresso econômico, social, cultural e humano às realidades para as quais se dirigiam. Essa é a narrativa utilizada para falar sobre a emigração italiana, sobre a presença italiana no continente americano, por exemplo, como os imigrantes provenientes da península itálica colaboraram para o desenvolvimento das comunidades para as quais se deslocaram.

Inclusive, é destacada a permanência linguístico-cultural, os hábitos que os descendentes mantiveram, o vínculo com a Itália que não desapareceu com o tempo. Diferentemente, quando se fala do imigrante na realidade italiana, o fato de manter uma ligação com a cultura da terra de proveniência se transforma em um problema e a contribuição que esse sujeito pode trazer é o apagamento da sua vida anterior. Possivelmente, esses espaços "bárbaros" dos quais agora afluem as levas atuais de imigrantes em direção à fortaleza Europa (e à Itália), são a representação do processo oposto àquele civilizatório; portanto, esses indivíduos devem ser contidos para não barbarizar o país e o continente.

A mesma Treccani - a partir de dois outros verbetes - oferece uma outra reflexão, com um olhar diferente sobre os processos sociais e, especificamente no interesse do presente artigo, com relação àqueles migratórios: o substantivo “inclusão" e o verbo "inserir". No que tange ao primeiro, é digno de nota que ele traz em si o segundo, na medida em que a sua formulação o descreve enquanto o ato de inserir em um conjunto:

Inclusão: O ato, o fato de incluir, ou seja, de inserir, de compreender em uma série, em um todo: i. de um nome na lista dos vencedores; i. de algumas cláusulas cautelares em um contrato. (TRECCANI, 20--) 
Considerando a proposição acima, o verbete “inclusão” não está indicando a ação de aperfeiçoar alguma coisa defeituosa, que deve ser completada; pelo contrário, fala do ato de compreender, no sentido de passar a fazer parte de uma série. Como se denota da citação, a inclusão de um nome em uma lista de indivíduos selecionados/classificados não significa uma alteração nem do nome, nem do sujeito, nem da própria lista, pressupõe uma justaposição destes diferentes elementos, sem que com isso sejam deformados.

Aprofundando a questão, como tinha sido assinalado anteriormente, quando se fala de "inclusão", faz-se referência ao ato de "inserir", que sugere o acréscimo de alguma coisa:

Inserir: De pessoa, torna-se parte de um grupo, de um ambiente; Introduzir uma obra (mesmo literária ou artística), em um texto, em um complexo orgânico [...] um elemento acrescentando [...]: o arquiteto quis i. na fachada um motivo decorativo; i. um episódio autobiográfico in um conto; i. uma citação, algumas notas em um texto (TRECCANI, 20--)

Seguindo a ideia expressa na formulação acima, "inclusão" diferentemente da noção de aperfeiçoamento implícita no conceito de "integração" - apresenta a imagem de um motivo decorativo que é inserido na fachada de um prédio, algo novo, diverso, que faz parte do próprio frontispício, mas - ao mesmo tempo - mantém aquelas que são as suas características originárias, peculiares. Por um lado, é possível distinguir a individualidade do motivo decorativo que foi anexado e, por outro, pode-se perceber também o conjunto, a série, a fachada em modo global, da qual o elemento acrescentado passa a fazer parte. No entanto, esse processo de "tornar-se parte de" não significou o apagamento ou a transformação das especificidades do elemento acrescentado; as suas qualidades intrínsecas foram mantidas e utilizadas para enriquecer a totalidade que representa a fachada.

Neste ponto da análise, é clara a ideia de que a integração se transforma no instrumento para a neutralização de um medo - por parte da sociedade da terra de chegada - aquele da subversão trazida pelo imigrante. No entanto, acaba se transformando na busca da solução de um outro medo, aquele do imigrante, de não ser reconhecido e aceito naquela comunidade que ele quer enxergar 
como de acolhida. Para não ser percebido como "o outro", a consubstanciação dos adjetivos negativos que dão significado ao sujeito imigrado e o transformam na encarnação do perigo, o imigrante "escolhe" deixar-se completar com os códigos culturais compartilhados que esta comunidade imaginada entende como seus: a integração transforma-se em uma via quase obrigatória. Na verdade, poder-se-ia dizer que o processo é ainda mais complexo, pois se observa uma diversidade de performances sociais que serão úteis aos imigrantes para produzir uma espécie de camuflagem, que tem como objetivo invisibilizar a presença deles no país em que desembarcaram, garantindo a aceitação, eliminando o sentido de perigo e restringindo o espaço do medo.

\section{Integração enquanto mimetismo social: uma solução para o medo}

De um lado, tem-se o indivíduo que deixou a terra em que nasceu para procurar uma vida melhor, ou até mesmo a possibilidade de sobrevivência em outro país, deixando atrás de si afetos, experiências, paisagens, códigos culturais, aquele que era o seu mundo, do outro, uma sociedade que espera que ele tenha um comportamento que corresponda àqueles aceitos pela cultura local. Em síntese, uma coletividade que pretende que os recém-chegados se deixem plasmar completamente, integrando-se na nova realidade, de acordo com o processo explicitado antes. Para o sujeito migrante, a única solução possível para ser aceito por parte da nova comunidade nacional em que vive - é aquela de construir uma performance que esteja em sintonia com as expectativas locais:

Confrontando-se com pessoas ou com situações que desestabilizam algumas partes da própria identidade, o sujeito entra em confusão. Busca o conforto de uma identidade mimata ${ }^{3}$ que limite as desvantagens, reduza os conflitos de ser simplesmente ele mesmo. Para se mimetizar então não basta imitar. Não basta olhar o outro e ser o reflexo de sua imagem, e reproduzi-la. É necessário também perceber, compreender como o outro nos vê. Criar, pois aquilo que se imita é conhecido, mas não è nunca evidente, se adapta às situações, às relações, à

\footnotetext{
Mantém-se o termo em italiano porque a possível tradução em português - imitar - não responde inteiramente ao sentido do verbo mimare. A ideia de "representar através de mímica" (mimare) traz consigo uma profundidade maior da sobreposição da relação que se estabelece entre imitador e imitado, que não se restringe aos gatos, mas busca adentrar seus significados mais profundos.
} 
individualidade de cada interação. (ROMANIA, 2006, p. 7, grifo do autor)

Verifica-se, então, uma situação desestabilizadora, como apontado anteriormente, entre as expectativas do imigrante e aquelas da sociedade na qual ele quer se estabelecer; consequentemente, é necessário, para que que possa haver a aceitação, mimare a identidade local. A ideia presente em mimare vai além da simples imitação, porque requer uma performance adaptativa que possa responder aos diferentes estímulos quotidianos da comunidade da terra de chegada; está relacionado a comportamentos que mudam nas interações específicas com cada pessoa, algo que deve ser construído para além do simples espelhamento.

Para poder responder de modo adequado à demanda de integração que provém da nova comunidade, o imigrado deve produzir representações de si que sejam aceitáveis na terra de chegada, e construir o seu comportamento em relação às expectativas do grupo no qual se encontra. Esse processo faz com que ele coloque em prática performances que sejam estrategicamente funcionais ao seu objetivo de ser aceito, independentemente da sua cultura de origem e do seu modo pessoal de interagir com as pessoas e com as situações quotidianas. O "bom imigrante" vai ser aquele sujeito capaz de produzir as performances mais adequadas e ajustadas para cada circunstância das dinâmicas sociais.

Romania (2006), quando fala de mimetismo social, sobre "fazer-se passar por", parte também de um pressuposto de plausibilidade, ou seja, terá mais sucesso o imigrante que tiver adquirido uma maior competência linguística e que possuir características fisionômicas mais facilmente assimiláveis à sociedade de acolhida. A performance pressupõe ainda a capacidade de reproduzir determinados sotaques ou mesmo formas linguísticas dialetais, indo além do modo de vestir e dos hábitos quotidianos. Isso se torna ainda mais importante na medida em que o imigrante deve parecer alheio àqueles estereótipos degradantes que são associados ao grupo ao qual pertence, que podem ser a representação do ladrão, da travesti, da prostituta, de qualquer forma, sempre 
vinculados a algum tipo de comportamento próximo a alguma tipologia de ilegalidade.

A performance social pode ser representada pelo uso de uma espécie de caixa de ferramentas, dentro da qual o imigrante vai procurar aquele comportamento adequado para atuar em cada situação:

Podemos imaginar cada indivíduo como um sujeito que se move entre diferentes situações, tendo consigo uma caixa com diferentes ferramentas culturais. Trata-se de instrumentos não ativos, mas potencialmente ativáveis. Portanto, de acordo com a situação, ele vai extrair da sua caixa os elementos mais úteis, para depois ativá-los e utilizar alguns, com o objetivo schutziano de resolver o problema da vida quotidiana. (ROMANIA, 2006, p. 26)

Segundo Vincenzo Romania, trata-se de um "processo instrumental e situacional de ocultamento das próprias peculiaridades culturais, patrimônio que ainda assim sobrevive na esfera íntima" (ROMANIA, 2006, p. 8). De acordo com o autor, não se verifica uma conformação total com relação à nova sociedade, mas à busca de obter vantagens práticas e privilégios no espaço público. Faz-se referência a um agenciamento racional da identidade, de um cálculo das relações entre custo e benefício na negociação de partes da própria identidade. O problema principal, tendo em conta o medo da não aceitação, como será analisado mais adiante, é que em alguns casos esse processo vai além da esfera pública e produz uma série de apagamentos de comportamentos e hábitos, inclusive do uso da língua nativa, que envolvem a esfera privada. A luta pelo reconhecimento e pela aceitação acabam indo além do agenciamento racional da esfera pública, levando a transformações culturais que envolvem a vida familiar e a própria autorrepresentação do imigrante: quanto mais morto for o sujeito pré-imigração, mais avançado será o processo de integração.

\section{Um olhar para as fontes no trabalho com a História Oral}

Antes de analisar como as fontes iluminam a discussão teórica apresentada e como nos dão indícios sobre o impacto do medo no comportamento dos imigrantes, é importante apontar algumas reflexões importantes sobre os documentos orais selecionados e sobre o tipo de sujeito 
entrevistado. Em primeiro lugar, as entrevistas que serão aqui analisadas foram realizadas nas regiões da Toscana e do Vêneto, assim como na província de Trento, entre 2005 e 2014, com dois grupos específicos de sujeitos: (1) mulheres provenientes dos países do Mercosul e (2) jovens ítalo-brasileiros, na maior parte estudantes universitários, residentes na zona nordeste da Itália ${ }^{4}$. No uso das fontes orais, decidiu-se pelo uso de entrevistas semiestruturadas, levando em consideração duas estratégias: história temática - na qual o fenômeno imigratório era o objeto central - e história de vida, porque os processos que envolveram a experiência migratória são entrecruzados com a narrativa do vivido ${ }^{5}$.

Quando se fala em narrativa oral, parte-se do pressuposto que o momento da entrevista é também o espaço de elaboração da fonte, que posteriormente irá se transformar no documento a ser analisado. No ato de contar a sua experiência, o/a entrevistado/a produz cortes, enfatiza alguns aspectos sobre o seu vivido, relê momentos específicos do passado, constrói uma legibilidade dos eventos pessoais e coletivos que vivenciou. Em um certo sentido, pode-se vislumbrar um processo de transliteração do passado pessoal e coletivo, porque a memória, como sugere Maurice Halbwachs, constrói-se na intersecção das lembranças, em que a experiência individual é atravessada por aquela coletiva, em um processo de retroalimentação (HALBWACHS, 1994).

Outro fenômeno importante que marca a produção das fontes orais, a partir da entrevista, está relacionado com a construção da lógica da narrativa. Partindo do pressuposto que a memória é constituída de fragmentos do vivido e que nenhum indivíduo é capaz de recordar a totalidade dos eventos que experimentou no passado, o ato da entrevista se torna também o momento de dar uma linearidade discursiva a esses fragmentos que caracterizaram o vivido pessoal e/ou coletivo. Nesse sentido, durante o ato narrativo, o entrevistador

\footnotetext{
${ }^{4}$ Foram realizadas mais de 50 entrevistas em diferentes projetos, dos quais se cita: "Retorno às raízes? Gênero, identidade e integração na imigração brasileira contemporânea na Itália”, financiado pelo CNPq (Edital MCT/CNPq/SPM-PR/MDA no 20/2010) e "Os pequenos pontos de partida: das colônias de imigração do sul do Brasil rumo à Itália nesse início do século XXI", financiado pelo CNPq (Edital MCT/CNPq/SPM-PR/MDA no 20/2010). Em colaboração com a colega da UDESC, Profa. Dra. Gláucia de Oliveira Assis, que coordenou o segundo projeto.

${ }^{5}$ Com relação à discussão sobre a História Oral como história de vida ou temática, ver:

ALBERTI, Verena. Ouvir contar. textos em história oral. Rio de Janeiro: FGV, 2004.
} 
interfere o menos possível para evitar de bloquear o fluxo mnemônico, deixando o entrevistado livre para entrelaçar os fios de suas experiências.

Dessa maneira, observa-se um processo de estranhamento com a passeidade, porque o sujeito que lembra não é o mesmo que vivenciou a experiência passada. Como afirmava Marcel Proust, o reviver do passado é o encontro com diferentes "eus" que habitavam aqueles tempos/espaços (PROUST, 2002). Portanto, no momento do relato, o entrevistado revisita a sua vida na pele de uma outra pessoa, porque o tempo deixou somente os vestígios daquele "eu" que habitava a passeidade e que agora se transformou em narração e representação.

Nesse sentido, é claro que o passado existe em função do presente e que o segundo constrói a estrutura narrativa do primeiro. Como se pode perceber, a partir da leitura de Koselleck (1993) sobre a relação entre passado, presente e futuro, as dinâmicas mnemônicas são ancoradas no presente do indivíduo que recorda, mas também nos objetivos que este construiu para o seu futuro: a memória se torna um espaço de intersecção entre três temporalidades. Na medida em que o presente do indivíduo sofre um processo de mudança e o seu projeto de futuro é afetado, os fragmentos do passado acabam sendo agrupados a partir de uma nova lógica e com o objetivo de produzir uma narrativa diferente, que se conforma com a nova realidade.

\section{Entre ansiedade e medo, sentir-se extracomunitário}

Em uma rápida leitura da enciclopédia Treccani, o verbete extracomunitário é apresentado tanto como adjetivo quanto como substantivo. No primeiro caso, indica uma condição geográfica, fazendo referência aos indivíduos que não pertencem à União Europeia, também identificada como "Comunidade Europeia". No segundo, enquanto indicação de um sujeito, o termo adquire uma conotação negativa, sendo associado aos imigrantes provenientes de "países economicamente desfavorecidos" (TRECCANI ONLINE, 20--). Nos meios de comunicação e na burocracia do Estado, vai ser este segundo significado de extracomunitário aquele que será mais usado, trazendo consigo as ideias de ilegalidade, criminalidade ou invasão de bárbaros. Esse termo será 
utilizado como a representação principal do mau imigrante, aquele que deve ser excluído da vida da civitas.

Os imigrantes latino-americanos ${ }^{6}$, que compõem o grupo de entrevistados apresentados neste artigo, se dão conta com muita clareza do enquadramento negativo que recebem, enquanto extracomunitários. É muito claro principalmente nas interações com a burocracia do Estado - e especialmente nos procedimentos necessários para obter a permissão de permanência no país. Além da imensa fila (que na maior parte das vezes já começa a ser formada durante a noite) e do risco de não conseguir ter acesso à senha do dia para poder ser recebido, a atitude dos agentes de polícia (sem contar as diferenças culturais) produz uma sensação ainda maior de não humanidade, de inferioridade, que terminam por dar uma maior conotação negativa a essa denominação de extracomunitário.

Nesse sentido, a fala de Pilar ${ }^{7}$, imigrante argentina que vivia na Itália fazia oito anos, quando foi realizada a entrevista, em 2005, na província de Arezzo (Toscana), é muito clara na definição daquilo que a fazia sentir exatamente como um extracomunitário. Desde a busca pela casa, ela teve que agenciar a sua identidade, construindo uma performance que fosse funcional para o seu objetivo: encontrar uma moradia para alugar. Procurou por muito tempo uma locação, como conta na entrevista, e - mesmo aumentando sempre mais a soma de dinheiro que estava disposta a oferecer - não conseguia encontrar uma residência disponível. Quando se deu conta do motivo pelo qual não estava achando "nem mesmo um buraco", como dizia, para alugar, mudou o modo como se apresentava: eliminou todo indício que a pudesse identificar como uma imigrante $^{8}$, logo, extracomunitária. Pilar, que tinha deixado o seu cargo de

\footnotetext{
${ }^{6}$ Para a análise do presente artigo foram escolhidos três entrevistados (Pilar, Helena e Mateus), do universo de mais de 50 entrevistas disponíveis. Considera-se que esses sujeitos oferecem um olhar panorâmico sobre o problema e que suas narrativas são emblemáticas com relação ao modo como os imigrantes afrontam estas questões. Além disso, são representativos com relação à proveniência e faixa etária, no que tange à totalidade das entrevistas.

A língua acordada para a entrevistada foi o italiano que era veículo comum de comunicação entre o entrevistador e a entrevistada, de língua materna espanhola.

${ }^{8}$ Como apresentado com relação ao sujeito "extracomunitário", também o migrante traz consigo uma carga negativa forjada em um estereótipo de baixo nível econômico, cultural, de civilização. Apresentar-se como um professor universitário significava sair deste "lugar social" e adentrar aquele do "estrangeiro", este associado não somente a regiões ricas do planeta, mas também a uma condição social abastada.
} 
professora universitária na Argentina, apresentava-se agora como uma professora argentina, especialista em História da Arte, que estava procurando uma residência para um período de estudos na Toscana. Como enfatizou a própria entrevistada, de mansões a palácios, não faltaram ofertas de aluguel (PILAR, 2004).

No entanto, a questão central que Pilar quer enfatizar está relacionada com a experiência da Questura (chefatura de polícia), aquela da entrega dos documentos necessários para a concessão da permissão de permanência. De acordo com o seu relato, este é o lugar por excelência em que o imigrante se sente um extracomunitário, no significado que a enciclopédia atribui ao substantivo. Em especial, a Questura se transforma em um imenso obstáculo que deve ser superado, uma prova na qual é fundamental ser aprovado para poder entrar nesta nova sociedade com tudo em ordem, de modo legal:

Se o problema era o imigrante, nos vimos muito mal, eh. Porque, mesmo se uma pessoa se esforçava muito e conseguia fazer tudo, todas às vezes que ia a Questura, para obter a bendita permissão de permanência, nos sentíamos muito mal, muito agredidas. Uma situação muito, muito difícil de resolver. E, certamente, tem gente que abandona tudo e volta [para o seu país], porque não consegue. Somente para "jogar o jogo" é preciso muita coragem [...]. (PILAR, 2004, tradução nossa) ${ }^{9}$

A Questura é vivida como uma experiência de agressão, porque - mesmo com todo o esforço pessoal, mesmo com todo o sofrimento vivido para chegar até o guichê, mesmo tendo respeitado todos os passos do procedimento - ainda assim o tratamento era depreciativo. De fato, a entrevistada argentina se qualifica como o grupo dos corajosos, dos fortes, aqueles sujeitos que conseguem superar o obstáculo da Questura, porque, mesmo com todas as dificuldades, conseguiram vencer e obter a permissão de permanência. Por outro lado, existem aqueles que - diferentemente - acabam sucumbindo a esse oceano de

\footnotetext{
${ }^{9}$ Versão na língua original: "Se il problema era l'immigrante, noi ce la siamo viste abbastanza difficile, eh. Perché nonostante mettere tutto l'impegno e riuscire a fare tutto, ogni volta che si andava in Questura, a fare il benedetto permesso di soggiorno, noi ci siamo sentite sempre molto, molto, aggredite. Una situazione molto, molto, difficile da risolvere. E, certamente, c'è gente che abbandona e se ne torna, perché non ce la fa'. Soltanto a seguire questo gioco, bisogna avere un gran coraggio."
} 
burocracia, desconfiança e agressão, tomando então a decisão de retornar aos seus países de proveniência ${ }^{10}$.

Mesmo reconhecendo que é natural a existência de uma legislação nacional, independentemente do fato que uma pessoa possa estar de acordo ou não, Pilar vê nela mais um instrumento de exclusão: "mas, tudo bem, estas são as leis, que uma pessoa pode ser contrária, mas, de fato, te fazem sentir muito mais imigrante do que antes, não? Te fazem sentir um extracomunitário"11 (PILAR, 2004). Então, na leitura de Pilar, o extracomunitário é a alteridade negativa, o excluído, aquele que luta para poder fazer parte da comunidade da terra de chegada, mas que vive um constante não reconhecimento. Dessa forma, vive a constante ansiedade de não conseguir, de não superar o obstáculo, de não atravessar a porta de entrada; uma ansiedade de não ser aceito na nova terra. Identificado o seu inimigo, que reconhece nele mesmo, enquanto responsável último pela sua exclusão, busca neutralizar o perigo, para eliminar o medo, através da integração.

\section{O perigo neutralizado: integração e invisibilidade}

Em um contexto em que este outro, o imigrante, é a alteridade negativa do nativo, as soluções que alguns indivíduos escolhem é aquela de invisibilidade, que está relacionada com a integração enquanto apagamento de si mesmos, e da aceitação do não reconhecimento, estratégias para neutralizar o perigo que entendem constituído por eles mesmos. Na entrevista de Helena ${ }^{12}$, a imigrante brasileira que vive na Itália desde 1986, observa-se com muita força essa dinâmica de abandono da vida de antes para mergulhar completamente no papel

\footnotetext{
10 É importante salientar que todos os entrevistados estavam vivendo legalmente na Itália, com permissão de permanência regular ou com cidadania italiana reconhecida. Ainda, todos tinham uma formação universitária já concluída ou em curso quando da entrevista. Enfim, por uma questão de privacidade, serão utilizados somente pseudônimos e não o nome dos entrevistados, com o objetivo de não permitir que sejam identificados.

${ }^{11}$ Versão na língua original: “Però, va beh, queste sono le legge, che uno non po' andare contro, però veramente ti fanno sentire molto più immigrante che prima, non. Ti fanno sentire extracomunitario."

${ }^{12}$ Mesmo sendo brasileira, e compartilhando a mesma língua do entrevistador, o português, Helena preferiu utilizar o italiano como língua para a entrevista. Dizia que dominava melhor a nova língua, e que o seu português sofria muita interferência do italiano. A sua escolha é muito emblemática, com relação à busca de integração e reconhecimento, em uma conjuntura marcada pelo medo do diferente, tema central deste artigo.
} 
que é chamada a desempenhar na terra de chegada ${ }^{13}$. $\mathrm{Na}$ verdade, o discurso sobre a integração é incorporado na sua totalidade por Helena, mesmo se enxerga a experiência com uma conotação positiva:

Uma coisa da qual nunca gostei foi de frequentar ou de construir guetos. Não me parece justo estar em um lugar e se guetizar, ou seja, os estrangeiros ou os brasileiros [...] as pessoas que se guetizam propõem uma ideia negativa, ou seja, não gosto das coisas que vivo aqui, mas devo ficar aqui, neste, e fazer estas coisas. (HELENA, 2004, tradução nossa) $)^{14}$

Assim como tantos indivíduos da terra de chegada, também a imigrante Helena não consegue ver a diferença e o fato de cultivar a tradição do país de proveniência como fundamentais no processo de enraizamento em uma nova sociedade e cultura. Formar grupos com os compatriotas que viveram experiências semelhantes de expatriação, na sua opinião, é um erro, porque produz o que ela chama de ghetizzazione, ou seja, constrói-se um gueto, entendido como lugar fechado e ensimesmado. Esses enclosures, segundo a entrevistada, transformam-se em espaços de crítica às interações, ao comportamento, a como as coisas eram feitas na comunidade em que tinham se estabelecido.

Helena relata uma experiência muito positiva na sua busca de aceitação na comunidade em que vivia/vive, falando sobre as estratégias de inserção/inclusão que foram utilizadas por ela:

Ficando mais tempo em San Giovanni, comecei a vivê-la, ou seja, a i rum pouco no centro da cidade, para ter contato com as pessoas, para procurar coisas para me inserir, e uma destas coisas que fiz, foi o trabalho como voluntária: trabalho de voluntariado para a assistência de pessoas hospitalizadas. Depois, o trabalho como voluntária junto a associações de proteção dos animais: no

\footnotetext{
13 Destaca-se que Helena chegou na Itália ainda antes do grande aumento do fenômeno migratório e de seu impacto nos meios de comunicação, com os desembarques de albaneses da região da Puglia. A percepção do imigrante na década de 80 do século XX não possuía ainda a forte conotação negativa adquirida posteriormente, a partir da última década do século, consequência do forte boom de chegada dos albaneses. Nesse sentido, ela ainda lembra a liberdade que vivia na Itália de então, com a possibilidade de andar pelas ruas sem documento algum, sem uma conta corrente e sem existir para o Estado Italiano.

${ }^{14}$ Versão na língua original: "Una cosa che non mi è mai piaciuta, è frequentare e fare ghetto. Non mi sembra giusto stare in un posto e ghettizzarsi, cioè, gli stranieri o i brasiliani. [...] Le persone che si "ghetizano" propongono un'idea negativa, cioè, non mi piacciono queste cose che vivo qui, però, devo rimanere qui, in questo, e fare queste cose."
} 
começo, acolhia os gatinhos abandonados pelas ruas, que eram trazidos até a associação [...]. (HELENA, 2004, tradução nossa) $)^{15}$

No entanto, esses trabalhos sociais junto às instituições e associações da cidade em que vivia são parte de uma busca por reconhecimento e aceitação, que na verdade trazem consigo o abandono daquela Helena que existia antes da imigração. O itinerário de inserção comunitária (que se parece mais com um caminho em direção à integração), na percepção de Helena, significa apagar a sua vida anterior - aquela da terra de partida, no Brasil - para viver melhor o ambiente no qual se encontra hoje:

Procurei viver as coisas deste lugar, este ambiente, desta cultura. Arranquei de mim, mentalmente, a minha vida de antes. [...] tem uma riqueza de experiências diferentes que não me deixam pensar naquilo que eu vivi um dia. (HELENA, 2004, tradução nossa $)^{16}$

Mesmo fazendo uma leitura positiva, enfatizando como a riqueza de diferentes experiências substitui aquelas que foram as suas vivências anteriores, o significado concreto está relacionado à necessidade de anular-se para poder fazer parte de uma nova comunidade. No caso da entrevistada, como se observa das citações utilizadas, esse processo foi tão profundo, que a levou a perder progressivamente a língua materna, que era o português, adquirindo um italiano com um sotaque muito local. Considerando que a imigrante brasileira chegou já em idade adulta, com instrução superior e tendo deixado uma função de magistério no sul do Brasil, a perda linguística se transforma em um emblema dessa busca do apagamento da vida passada.

A ideia da integração como forma de neutralizar o medo da não aceitação e reconhecimento se torna ainda mais clara quando mais adiante, na entrevista, Helena afirma que abandona os seus interesses - na esfera pública, mesmo

\footnotetext{
15 Versão na língua original: "Rimanendo più tempo a San Giovanni, ho cominciato a viverla, Cioè, ad andare un po' in città, a cercare le persone, a cercare cose per inserirmi e una di queste cose che ho fatto è stato il lavoro volontario: il lavoro volontario per l'assistenza alle persone in ospedale. Dopo, il lavoro volontario presso associazioni di protezione degli animali - all'inizio raccoglieva i gattini abbandonati per le strade, che erano portati all'associazione [...]."

${ }^{16}$ Versão na língua original: Ho cercato di vivere le cose di questo spazio, di questo ambiente, di questa cultura. Ho strappato di me, mentalmente, la mia vita di prima. [...] c'è una ricchezza di vissuti diversi che non mi fanno pensare a quello che una volta ho vissuto."
} 
continuando a existir e tomar o seu tempo na esfera privada - para viver com os outros somente aqueles que são os interesses deles:

Os meus interesses são ainda os meus interesses, mas individuais, não os compartilho com os outros. Como s outros, eu compartilho os interesses deles. Certamente eu trago comigo a minha bagagem, com todos os meus interesses, etc., etc., mas procuro viver aqueles dos outros. (HELENA, 2004, tradução nossa $)^{17}$

Na compreensão da imigrante, a sua bagagem pessoal e cultural não tem nada para oferecer na sociedade em que vive, porque não é percebida como algo positivo para o bom êxito de um processo de aceitação, reconhecimento e integração. Diferentemente, para ela, viver os interesses das pessoas com as quais se relaciona na província de Arezzo significa começar a fazer parte do quotidiano daquela comunidade, ser aceita pelos nativos, passar a pertencer àquele grupo.

Em uma outra realidade geográfica e etária, no caso de Mateus ${ }^{18}$, jovem imigrante brasileiro originário do Espírito Santo, que viveu uma forte situação de exploração de seu trabalho, na região do Trentino Alto Adige, aceitação, reconhecimento e integração são uma realidade impossível de ser atingida. $\mathrm{Na}$ sua opinião, não é somente uma questão legal, considerando que ele tem a cidadania italiana (mesmo tendo nascido no Brasil), segundo o critério do lure Sanguinis utilizado na Itália, mas a causa deve ser buscada na grande diferença cultural que não é aceita na comunidade da nova terra:

cê nunca vai ser um deles, cê nunca vai ser, por mais que cê tenha cidadania, por mais que cê tenha o nome deles, nunca, porque mesmo talvez na falada vai ficar um sotaque, então, vão notar, vão te perguntar, a tua história, não adianta, não muda. (MATEUS, 2013)

Na leitura de Mateus, a integração efetiva é um objetivo inatingível, porque o imigrante nunca vai ser completamente igual ao nativo, nunca vai conseguir compartilhar plenamente os códigos culturais da terra de chegada, vai sempre

\footnotetext{
17 Versão na língua original: "I miei interessi sono ancora i miei interessi, ma individuali, non li condivido con gli altri. Con gli altri io condivido i loro interessi. Certamente, porto con me il mio bagaglio, con tutti i miei interessi ecc, ecc, ma cerco di vivere quelli altri."

${ }^{18} \mathrm{O}$ entrevistado - brasileiro - preferiu utilizar a língua portuguesa para a entrevista.
} 
haver alguma coisa que irá desmascarar a sua performance e que vai mostrar à comunidade que ele é o outro. A própria Helena, durante a entrevista, afirmou que quando dizia que era brasileira (depois da pergunta que seguia algum erro gramatical ou alguma pronúncia incomum - de onde você é?), a conversa tomava outro rumo e o diálogo acabava sendo sexualizado.

\section{Considerações finais}

Neste artigo, buscou-se analisar, no contexto da imigração latinoamericana contemporânea, na Itália, o medo do outro como ponto de partida para a construção da intolerância - de uma intransigência com relação ao diferente - e como a integração se constitui em um "remédio" que produz resignação, como sintoma de uma busca de reconhecimento e aceitação na terra em que se quer viver. Seja como representação veiculada pelos meios de comunicação, seja como objeto do discurso político, ou como imaginário que se enraizou na comunidade que os recebe, o outro está identificado ao medo de uma mudança em negativo, à destruição daquilo que a comunidade imaginada reconhece como sua tradição imutável.

Se a integração se apresenta como uma neutralização das características subversivas da alteridade, ela impede essa ação perturbadora, porque procura cancelar o seu passado, a sua cultura. Também para o imigrante, no contexto de preconceito com relação ao seu grupo de proveniência, a integração o neutraliza como inimigo da sociedade da terra de chegada, deixando-o constantemente ansioso com relação às possibilidades de aceitação e reconhecimento. Portanto, cria-se uma ideia transversal sobre a integração, de que ela se apresenta como a solução definitiva para o "problema" do outro na comunidade nacional, fazendo da morte de suas especificidades culturais a salvação da nação.

No entanto, como afirma Mateus, mas também como observa Helena, comentando o quanto uma nota de sotaque estrangeiro leva à pergunta sobre a sua origem e, consequentemente, ao uso do estereótipo da mulher brasileira, com uma mudança no tema da conversação, sempre vai haver algo que irá desmascarar esse pertencimento à terra de chegada. Naquele momento, não obstante os esforços para uma total integração, para mimetizar-se na nova 
realidade, fazendo-se passar por alguém do lugar, a imagem da alteridade vem à tona. Não se é mais alguém do grupo, com ou sem cidadania reconhecida, mas se passa a fazer parte de um outro conjunto, aquele da alteridade.

Dessa forma, mesmo que em um primeiro momento a integração seja projetada como uma solução eficaz e definitiva para neutralizar o perigo do outro, a ameaça estará sempre latente. Especialmente o imigrante, vive constantemente receoso de ser descoberto na sua condição de alteridade, com o risco de não ser aceito e reconhecido como parte da comunidade. Nesse sentido, a ideia de inclusão - que pressupõe inserir um sujeito ao interno de uma comunidade, sem descaracterizá-lo - poderia se configurar em uma resposta melhor ao fenômeno migratório, principalmente considerando que a integração, além de se tornar um processo de apagamento do outro, não produz os efeitos de aceitação e reconhecimento plenos ao interno da comunidade onde o imigrante se estabelece: em algum momento, os estereótipos negativos que caracterizam as coletividades nacionais imigradas virão à tona. Diferentemente da ideia de integração, que - ao procurar apagar as experiências da terra de nascimento - não permite com a diversidade o enriquecimento da comunidade, a noção de inclusão alude à manutenção das especificidades culturais dos imigrantes, gerando, em potência, uma possibilidade de crescimento coletivo, com aquilo que é específico de cada grupo. 


\section{Referências}

ANDERSON, Benedict. Comunità immaginate: origini e fortuna dei nazionalismi. Roma: Laterza, 2018.

BONIFAZI, Corrado. L'immigrazione straniera in Italia. Bologna: Il Mulino, 2007.

BOURKE, Joanna. Fear and anxiety: writing about emotion in modern history. History Workshop Journal, Oxford, n. 55, p. 111-133, primavera 2003.

CALVANESE, Ernesto. Media e immigrazione tra stereotipi e pregiudizi: la rappresentazione dello straniero nel racconto giornalistico. Milano: FrancoAngeli, 2011.

DELUMEAU, Jean. La peur en occident (XIVe-XVIII siècles): une cité assiégée. Paris: Fayard, 1978.

EINAUDI, Luca. Le politiche dell'immigrazione in Italia dall'Unità ad oggi. Roma: Laterza, 2007.

EXTRACOMUNITARIO. In: TRECCANI, vocabolario online. Roma: Istituto dell’Enciclopedia Italiana, 20--. Disponível em:

https://www.treccani.it/vocabolario/extracomunitario/. Acesso em: 8 set. 2021.

FALOPPA, Federico. Razzisti a parole (per tacer dei fatti). Roma: Edizioni Laterza, 2011.

HALBWACHS, Maurice. Les cadres sociaux de la mémoire. Paris: Édition Albin Michel, 1994.

HELENA [Entrevista cedida a] Luís Fernando Beneduzi, San Giovanni Valdarno (IT), 16 nov. 2004.

INCLUSIONE. In: TRECCANI, vocabolario online. Roma: Istituto dell'Enciclopedia Italiana, 20--. Disponível em: https://www.treccani.it/vocabolario/inclusione/. Acesso em: 8 set. 2021.

INSERIRE. In: TRECCANI, vocabolario online. Roma: Istituto dell'Enciclopedia Italiana, 20--. Disponível em: https://www.treccani.it/vocabolario/inserire/. Acesso em: 8 set. 2021.

INTEGRAZIONE. In: TRECCANI, vocabolario online. Roma: Istituto dell'Enciclopedia Italiana, 20--. Disponível em:

https://www.treccani.it/vocabolario/integrazione/. Acesso em: 8 set. 2021.

LINHARD, Tabea; PARSONS, Timothy. Mapping migration, identity, and space. Nova York: Palgrave, 2019.

MATEUS [Entrevista cedida a] Luis Fernando Beneduzi, Trento, 16 jun 2012. 
KOSELLECK, Reinhart. Futuro pasado. Barcelona: Paidós, 1993.

PILAR [Entrevista cedida a ] Luís Fernando Beneduzi, San Giovanni Valdarno (IT), 29 nov. 2004.

PROUST, Marcel. Em busca do tempo perdido. Rio de Janeiro: Ediouro, 2002.

ROMANIA, Vincenzo. Farsi passare per italiani: strategie di mimetismo sociale. Roma: Carocci, 2006.

STEARNS, Peter. Fear and contemporary history: a review essay. Journal of Social History, Oxford, v. 40, n. 2, p. 477- 484, inverno 2006. 